\title{
RESEARCH
}

Open Access

\section{Liver-lung interactions in acute respiratory distress syndrome}

\author{
Raquel Herrero ${ }^{1,2,3^{*}}$ (D) Gema Sánchez ${ }^{3,4}$, Iris Asensio ${ }^{5,6}$, Eva López ${ }^{3}$, Antonio Ferruelo², Javier Vaquero 5,6 , \\ Laura Moreno ${ }^{2,7}$, Alba de Lorenzo ${ }^{3}$, Rafael Bañares ${ }^{5,6}$ and José A. Lorente ${ }^{1,2,3,8}$
}

From 4th International Symposium on Acute Pulmonary Injury and Translational Research - INSPIRES 2019

Dresden, Germany. 25-26 November 2019

\footnotetext{
*Correspondence: raquelher@ hotmail.com

'Department of Critical Care Medicine, Hospital Universitario de Getafe, Madrid, Spain

${ }^{2}$ CIBER de Enfermedades

Respiratorias, Instituto de Investigación Carlos III, Madrid, Spain

Full list of author information is available at the end of the article
}

\begin{abstract}
Patients with liver diseases are at high risk for the development of acute respiratory distress syndrome (ARDS). The liver is an important organ that regulates a complex network of mediators and modulates organ interactions during inflammatory disorders. Liver function is increasingly recognized as a critical determinant of the pathogenesis and resolution of ARDS, significantly influencing the prognosis of these patients. The liver plays a central role in the synthesis of proteins, metabolism of toxins and drugs, and in the modulation of immunity and host defense. However, the tools for assessing liver function are limited in the clinical setting, and patients with liver diseases are frequently excluded from clinical studies of ARDS. Therefore, the mechanisms by which the liver participates in the pathogenesis of acute lung injury are not totally understood. Several functions of the liver, including endotoxin and bacterial clearance, release and clearance of pro-inflammatory cytokines and eicosanoids, and synthesis of acute-phase proteins can modulate lung injury in the setting of sepsis and other severe inflammatory diseases. In this review, we summarized clinical and experimental support for the notion that the liver critically regulates systemic and pulmonary responses following inflammatory insults. Although promoting inflammation can be detrimental in the context of acute lung injury, the liver response to an inflammatory insult is also pro-defense and prosurvival. A better understanding of the liver-lung axis will provide valuable insights into new diagnostic targets and therapeutic strategies for clinical intervention in patients with or at risk for ARDS.

Keywords: Liver-lung interaction, Acute respiratory distress syndrome, Liver dysfunction, Mechanisms, Immunomodulation, Acute-phase response, Critical illness
\end{abstract} original author(s) and the source, provide a link to the Creative Commons licence, and indicate if changes were made. The images or other third party material in this article are included in the article's Creative Commons licence, unless indicated otherwise in a credit line to the material. If material is not included in the article's Creative Commons licence and your intended use is not permitted by statutory regulation or exceeds the permitted use, you will need to obtain permission directly from the copyright holder. To view a copy of this licence, visit http://creativecommons.org/licenses/by/4.0/. 


\section{Background}

Acute respiratory distress syndrome (ARDS) is a severe respiratory failure, due to noncardiogenic pulmonary edema [1,2], associated with a hospital mortality between $35 \%$ and 46\% [1, 3, 4]. The pathology of ARDS involves diffuse alveolar damage (DAD), which comprises severe alveolar epithelial cell damage, neutrophil infiltration, activation of alveolar macrophages, production of cytokines and chemokines, plasma extravasation, procoagulant activity with fibrin deposition, hyaline membrane formation, myofibroblast proliferation, and fibrosis in the intra-alveolar spaces [2, 4]. Formation of protein-rich edema in the airspaces due to the disruption of the alveolar-capillary membrane is one of the main factors that contributes to the severe impairment of blood and tissue oxygenation early in the evolution of DAD [2, 4]. The DAD occurs not only in response to a direct injury to the lung (e.g., pneumonia), but it may also represent a pulmonary manifestation of diverse systemic immunoregulatory disorders, such as sepsis [4]. The pathogenesis of ARDS, therefore, is linked to changes in local and systemic host defense and immune responses [5], in which the liver plays an important role (Fig. 1).

The liver has unique anatomic, cellular, and physiological characteristics that enable the clearance of circulating microbial products, tissue debris, altered platelets, products of intravascular coagulation, and different bioactive molecules (Fig. 1) [6-10]. Also, the liver has a key role in the synthesis of proteins, metabolism of toxins and drugs, and in the modulation of systemic inflammatory responses and host defense (Fig. 1). It is becoming more evident that normal liver function exerts lung protection and is necessary for recovery from lung damage $[11,12]$. In this line, it has been observed that established ARDS during acute liver allograft rejection is resolved within hours of

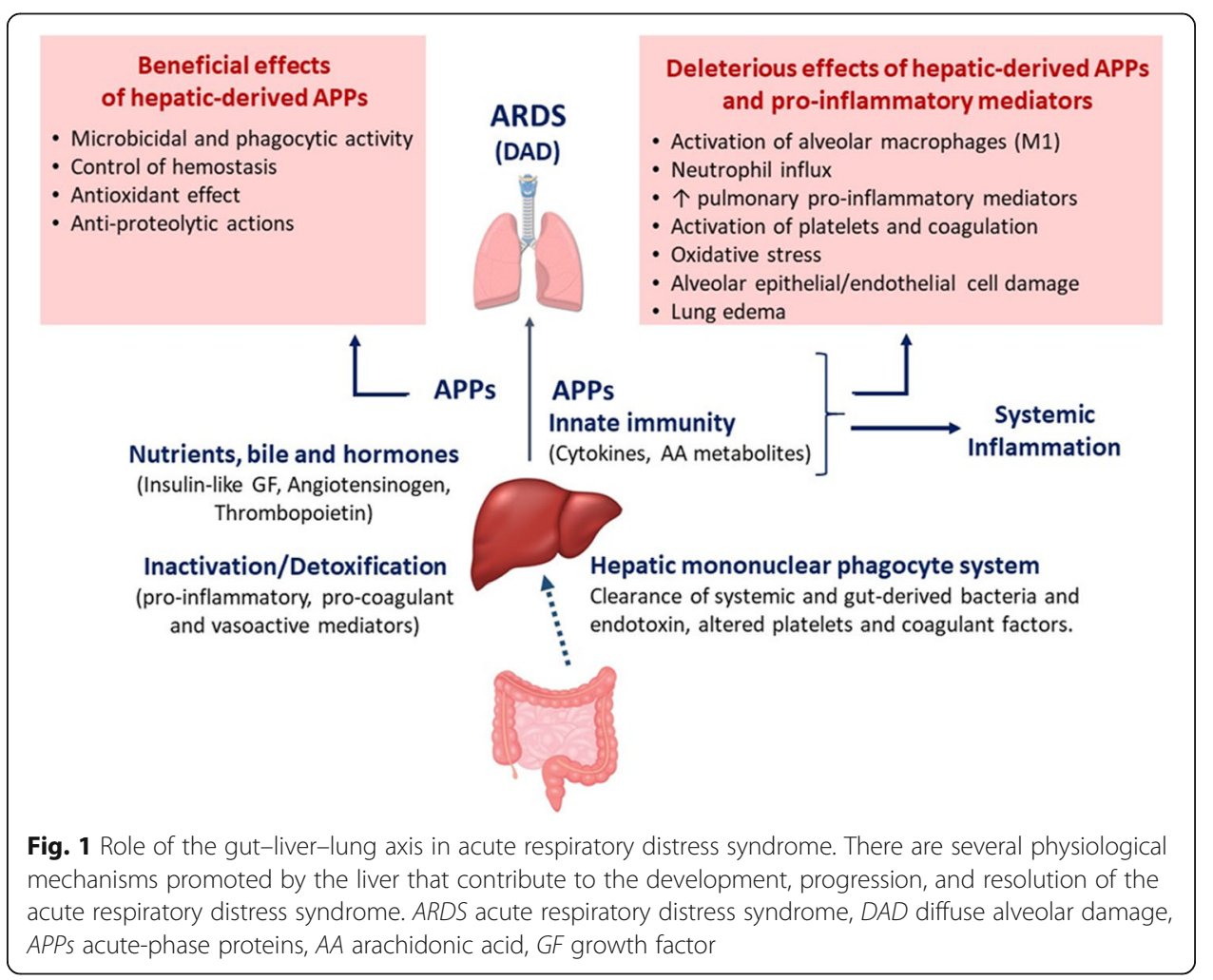


hepatic re-transplantation [13]. On the other hand, experimental studies suggest that the presence of the liver is also absolutely necessary for inducing lung injury in rats [14]. These apparently paradoxical observations highlight the relevant crosstalk between lung and liver in ARDS.

Despite the well-recognized liver-lung interaction in the pathogenesis of ARDS, its underlying mechanisms and its effects on the outcome of these patients have been barely studied due to several reasons. First, patients with liver diseases are frequently excluded from studies of ARDS. In addition, liver function is not precisely reflected by the standard liver function tests in the clinical setting, and the liver is not as accessible as other organs such as the lung, making liver dysfunction not as evident as dysfunctions of other organs. Finally, its clinical consequences are also heterogeneous in critically ill patients [15]. The present work reviews the important role of the liver on the development and resolution of ARDS and aims to provide an integrated view of the underlying mechanisms that support the liver-lung interaction in critically ill patients.

\section{The reciprocal impacts of lung and liver dysfunctions}

Following hepatocellular damage, the liver may reduce its clearance function, increase the synthesis of deleterious substances, and dysregulate immune responses, leading to systemic complications such as coagulopathy, elevated risk of infection, hypoglycaemia, exacerbated inflammatory responses, encephalopathy, and damage of other extrahepatic organs, including lung injury [16-22]. In critically ill patients, hepatic dysfunction is recognized as a relevant clinical condition that influences the development, severity, and progression of ARDS [5, 11, 19, 23-27]. In ARDS patients, liver dysfunction is a major determinant of mortality [24-26]. It is well known that cirrhosis and other chronic liver diseases make the patients more susceptible for developing ARDS, which adversely affects patient outcomes [24-26, 28]. A growing body of evidence suggests that liver damage activates and enhances inflammation in the pulmonary intravascular compartment and lower respiratory tract, leading to important changes in the structure and/or functions of the lung $[29,30]$. Although all these observations indicate that liver function is an important factor for the development and resolution of ARDS, there is also evidence that such interorgan communication is bidirectional. Thus, acute lung injury is known to impair hepatic function and to aggravate liver diseases by mechanisms involving hypoxemia, activation of systemic inflammatory responses, and cardiovascular changes [24, 31, 32].

\section{Liver dysfunction is common in critical care patients}

The frequency of liver damage in critical illness has considerably increased over the last decades [23,33-35], reaching up to $20 \%$ of ICU patients in some series and elevating their morbi-mortality $[33,34,36]$. In critically ill patients, liver dysfunction usually occurs after inflammatory insults such as sepsis and trauma $[15,23,33,37]$, and the underlying interactive mechanisms are complex. The mechanisms of liver dysfunction in critically ill patients implicate microbial products, the paracrine action of cytokines and other inflammatory mediators, hypoxemia, oxidative stress, toxic compounds, hypoperfusion, passive congestion, and effect of nutrition support, among others [34, 38-40]. 
Liver dysfunction can be manifested by plasma elevation of liver enzymes (aspartate aminotransferase (AST), alanine aminotransferase (ALT), alkaline phosphatase (ALP), $\gamma$-glutamyl transpeptidase) and bilirubin, decreased plasma levels of albumin and coagulation factors, and/or increased international normalized ratio (INR) [33, 36]. The clearance rate of indocyanine green has been used as a dynamic test to assess the functional capacity of the liver. Although the indocyanine green test has shown to reflect better the excretory and/or microvascular dysfunction of the liver, its clinical use has certain limitations [41]. Increased plasma levels of bilirubin are associated with high mortality in critically ill patients [39, 42]. Furthermore, hyperbilirubinemia has been proposed as a biomarker of ARDS and found to be an independent factor of mortality in patients with ARDS [26, 35, 39, 43]. Unfortunately, neither bilirubinemia nor other hepatic parameters routinely measured in the clinical setting have the sensitivity and specificity required for an early identification of hepatic injury in critically ill patients $[23,33,36,40]$.

\section{Mechanisms of liver-lung interactions in ARDS}

The mechanisms by which the liver modulates lung injury involve interrelated elements of systemic and pulmonary host defense, inflammatory responses, and metabolism and include the following (see Fig. 1).

\section{Clearance by the hepatic mononuclear phagocyte system of systemic endotoxemia, bacteremia, vasoactive by-products, and procoagulant factors}

The mononuclear phagocyte system located in the liver, spleen, lung, and bone marrow constitutes the major mechanism to uptake and detoxify bacteria, fungi, viruses, and dying cells, limiting the magnitude and duration of infections [10, 44, 45]. Although these mononuclear phagocytic cells can exert this function in all these locations, their major mass is in the hepatic sinusoids [10,46]. The hepatic sinusoid is a unique vascular structure with highly specialized endothelial cells (liver sinusoidal endothelial cells) and liver macrophages (Kupffer cells) that reside within the lumen. The cells of the hepatic sinusoid are constantly exposed to gut-derived bacteria, microbial debris, and bacterial endotoxins. Kupffer cells, which line the extensive sinusoidal network, constitute nearly $80-90 \%$ of the tissue macrophages present in the body and exert an important role in host defense through phagocytosis and a multitude of secretory functions [46]. The hepatic mononuclear phagocyte system acts as a first line of defense in clearing bacteria and their products. Besides uptake of microbial pathogens and products, Kupffer cells also protect the lung and other extrahepatic organs by removing altered platelets and intravascular coagulation products (Fig. 1) [8-10, 46].

Dysfunction of the reticuloendothelial system of the liver allows bacterial and microbial products, including the so-called pathogen-associated molecular patterns (PAMs) [47], to reach the lung and the systemic circulation, where they activate pulmonary and systemic inflammatory responses (Fig. 1) [29, 47-49]. Indeed, increased plasma levels of endotoxin, probably of intestinal origin, along with increased levels of some cytokines have been found in the blood of patients with acute and chronic liver diseases [50-54].

Pulmonary deposition of intravascular bacteria, and their products alter the structure and function of the lung by different mechanisms including (i) direct cytotoxic effect 
on alveolar epithelial and endothelial cells, (ii) modulation of local innate immune responses in the lung via activation of toll-like receptors (TLRs), resulting in activation of resident alveolar macrophages and neutrophil influx and in the production of reactive oxygen species, (iii) activation of the coagulation cascades and platelet aggregation, leading to pulmonary microvascular thrombosis [29, 48, 49, 55-59], and (iv) a sustainable increase in pulmonary vascular resistance [22, 30] (Fig. 2). All these mechanisms alter the alveolar endothelial and epithelial cell functions and enhance barrier permeability leading to the formation pulmonary alveolar edema and respiratory failure [14, 60], the two main characteristics of ARDS (Fig. 2).

\section{Metabolic inactivation and detoxification of endogenous inflammatory mediators}

The hepatobiliary system has an important capacity to inactivate and detoxicate proinflammatory cytokines, vasoactive mediators, and eicosanoids from the systemic circulation. Removal of all these mediators constitutes a critical element of systemic and pulmonary host defense, protecting the lung and other extrahepatic organs from injury (Fig. 1) [8-10, 46]. Like endotoxin, increased levels of cytokines (such as IL-8, IL-1 $\beta$, ENA-78, TNF- $\alpha$, MCP-1, MIP- $1 \alpha, \ldots)$ and arachidonic acid-derived eicosanoids (thromboxane, leukotrienes) not cleared by the liver have been shown to exert a direct cytotoxic effect on alveolar epithelial and endothelial cells, to activate local innate

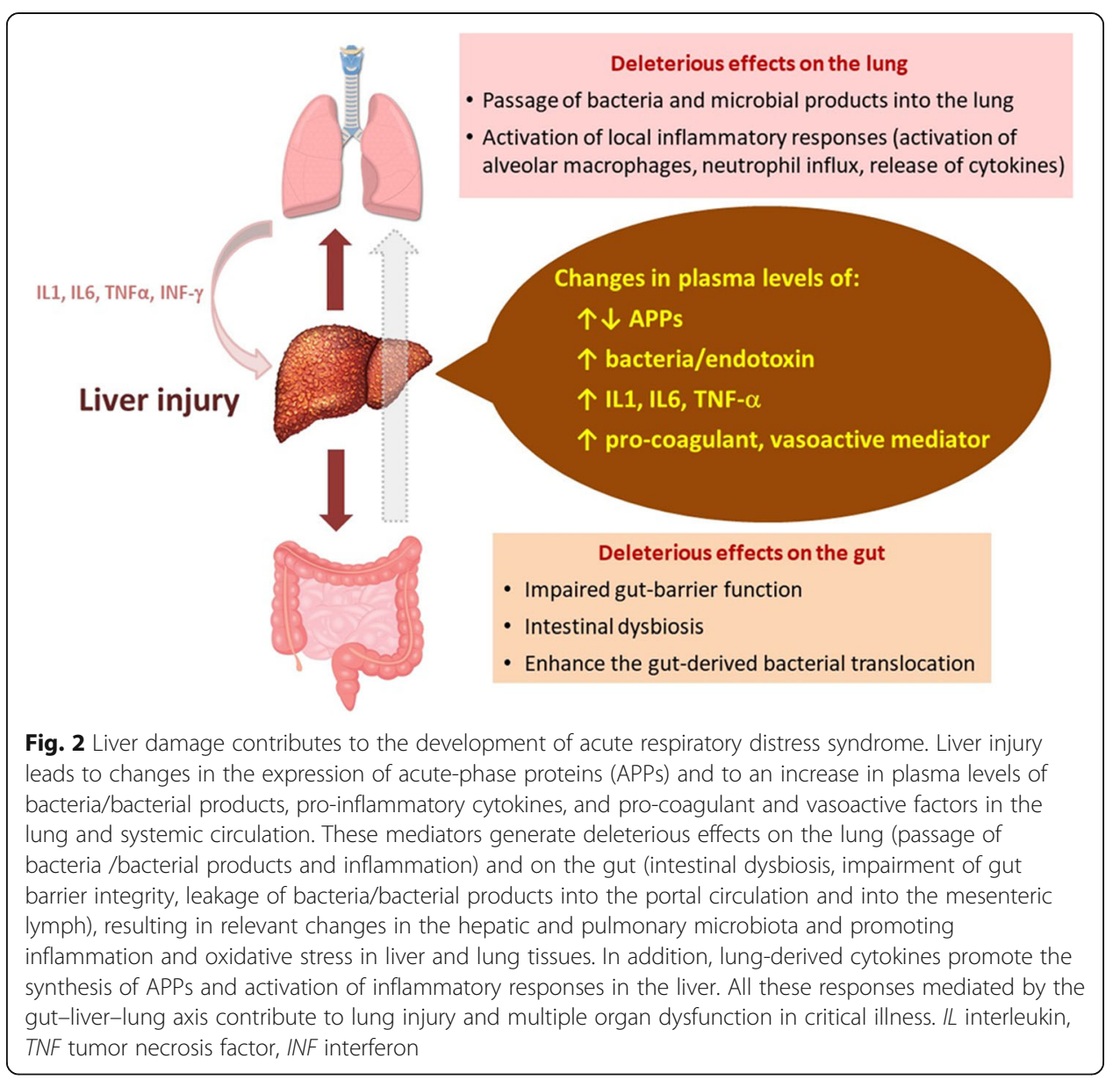


immune responses and to promote platelet aggregation in the lung, contributing to the development of diffuse alveolar damage (DAD) [55-59].

\section{Hepatic synthesis of inflammatory mediators that can activate pulmonary alveolar macrophages and, consequently, increase inflammation in the lung}

Hepatic mononuclear cells include a heterogeneous population of lymphocytes, Kupffer cells (hepatic resident macrophages), monocytes, and granulocytes that perform vital functions for the innate and adaptive immune system. In response to injury, activation of these hepatic mononuclear cells enhances the production and release of inflammatory mediators, such as IL-1, IL-6, TNF- $\alpha$, platelet-activating factor (PAF), and leukotrienes, into the systemic circulation [61], where they play an important role in the lung-liver interaction [18, 31, 51, 61-64]. These liverderived inflammatory mediators alter lung structure function early in acute inflammatory diseases (such as sepsis) and contribute to some extent to lung damage upon activation of pulmonary alveolar macrophages (Fig. 1] [17, 65]. In this line, elevated levels of TNF- $\alpha$ and IL-1 $\beta$, two cytokines that are mainly synthetized by alveolar macrophages, have been found in the lungs of rats with carbon tetrachloride (CCl4)-induced cirrhosis, along with an increase in lipid peroxidation (TBARS) and antioxidant enzymes (superoxide dismutase and catalase) in the liver and lung tissues. These events are also associated with altered gas exchange and changes in the size of pulmonary vessels in these rats [66, 67]. Besides high levels of endotoxin $[50,68]$, patients with liver disorders also have high circulating levels of TNF- $\alpha$, IL-1, and IL-6 [51-54] because of the altered capacity for inactivation and detoxification and the increased synthesis of pro-inflammatory mediators by the liver $[9,44,46,61]$. These specific cytokines have been shown to modulate systemic inflammatory responses and participate in the development of lung damage [69-72]. Therefore, it is possible that cytokines of hepatic origin may control and modulate the local host defense and immune system of the lung, contributing to lung injury (Figure 2).

\section{The liver is the main organ responsible for the acute-phase response}

The organism responds to tissue injury or infection by local changes such as those associated to inflammation and by a coordinated sequence of systemic and metabolic process, known as the acute-phase response, aimed to restore homeostasis and recover from injury [63, 73-76]. One of the mayor characteristics of this acute-phase response is a change in plasma concentration (either increase or decrease) of the acute-phase proteins (APPs) expressed in the liver [74]. Cytokine-driving synthesis of acute-phase proteins in the liver modulates the systemic and pulmonary host inflammatory responses and intermediary metabolism (Fig. 1) [22, 30, 48]. The hepatic APPs have a variety of functions that include microbicidal and phagocytic activity (e.g., LPS binding protein, complement components, C-reactive protein), recruitment of immune cells to inflammatory sites (e.g., serum amyloid A), hemostasis (e.g., fibrinogen, $\alpha 1$-acid glycoprotein), antioxidant, and prevention of iron loss (e.g., haptoglobin) and antiproteolytic actions to counterbalance protease activity at sites of inflammation (e.g., $\alpha 2-$ macroglobulin, $\alpha 1$-antitrypsin, and $\alpha 1$-antichymotrypsin) (Fig. 1) [63, 74, 75]. 
While the local inflammation occurs in the alveolar airspaces of patients with ARDS, the acute-phase response is induced in the liver [73, 76, 77]. Interestingly, in pneumonia-induced ARDS, this liver-derived acute-phase response occurs independently of bacterial dissemination and depends instead on inflammatory signaling molecules derived from the pulmonary immune cells, such as the cytokines IL-1, IL-6, and TNF- $\alpha[10,62,63,73,74]$. Then, these lung-derived cytokines can travel from the lung into the systemic circulation and ultimately modify acute-phase gene expression in the liver $[63,73,78,79]$ upon activation of the transcription factors STAT3 (signal transducer and activator of transcription 3) by IL-6 and activation of RelA (v-rel avian reticuloendotheliosis viral oncogene homolog A, also known as NF-kB3) by the earlyresponse cytokines TNF- $\alpha$ and IL-1 [73, 78, 79]. In response to these cytokines, the liver changes the expression of many acute-phase proteins such as $\mathrm{C}$-reactive protein, $\alpha-1$ antitrypsin, serum amyloid A protein, and others [10, 62, 63, 74, 77], which in turn can directly travel back to the lung and pass into the airspaces where they cause inflammation, predominantly via activation of alveolar macrophages (Fig. 2) [5, 14]. These phagocytic cells are targeted by multiple hepatic APPs such as SAA [80, 81], SAP [82], LBP [83], and C-reactive protein [84, 85]. Once activated by these hepatic APPs, alveolar macrophages release cytokines (IL-6 and CXCL1) that enhance local inflammation, in part by promoting neutrophil influx to the insterstitium and alveolar airspaces. Excessive inflammation in the alveoli may result in an increase in oxidative stress and lung injury [86, 87]. Besides this potentially deleterious effect, hepatic APPs at the site of plasma extravasation has other potential functions, including opsonization of bacteria, leukocyte activation, antiprotease, antioxidant activities, and modulation of the coagulation pathway $[63,75]$. These mechanisms help to regulate host defense, limit excessive inflammation and immune responses, and promote bacterial clearance, preventing infection dissemination and reducing the risk of organ damage in the setting of pneumonia and sepsis. Also, hepatic APPs exert liver protection by countering TNF-dependent toxicity in the liver and attenuate systemic inflammation and mortality in sepsis and pneumonia-induced ARDS (Fig. 1) [79, 86, 88-90]. Altogether, the bidirectional liver-lung axis mediated by APPs is critical for integrating systemic and pulmonary responses, balancing regulation of multiple host defenses and activation of inflammation to restore homeostasis and recover from organ injury $[48,61,86]$. Disbalance in this liver-lung communication can be an important factor in the initiation and progression of ARDS and of the damage to other organs [73].

\section{Nutrients, bile, and hormone production}

The liver plays an important role in regulating metabolic homeostasis and in the synthesis and processing of lipids and carbohydrates that supply energy to other organs [91]. It is also the major site of synthesis of key proteins and bile acids that are critical for the normal uptake of vitamins and lipids [92]. Therefore, alterations in the flux of carbohydrates and lipids through the liver can indirectly impact distal organs due to alteration of their energy statuses [93]. In addition, hyperbilirubinemia in the context of liver diseases has been shown to cause some lung-specific deleterious effects, by entering the lung tissue, reaching the alveolar airspaces, and deteriorating the surface 
tension properties of the alveolar surfactant [94]. Although bilirubin has antioxidant properties, high bilirubin levels can also activate oxidative stress, apoptosis, and inflammatory responses in different cell types and organs [95-98]. Therefore, hyperbilirubinemia may actively participate in the development of ARDS, although the underlying mechanisms have not been fully elucidated. Finally, the liver produces several hormones that mediate diverse extrahepatic effects, such as insulin-like growth factor, angiotensinogen, and thrombopoietin, which have been shown to influence the development of ARDS (Fig. 1) [55, 99, 100].

\section{The gut-liver-lung axis}

The pathogenic mechanisms of ARDS should be considered within a gut-liver-lung axis. Growing evidence indicates that intestinal microbiota and the mucosal immune system of the gut have an important impact on the function of the gastrointestinal tract itself and extra-intestinal organs, such as the lung and the liver [29, 48, 49]. Liver cirrhosis and other liver diseases favor the gut-derived bacterial translocation into the liver and lung by several mechanisms (Fig. 2).

First, patients with liver disorders have intestinal dysbiosis characterized by a significant shift of the microbial composition toward pro-inflammatory bacteria. This gut dysbiosis is accompanied by activation of local intestine immune responses and impaired gut barrier function. A leaky gut barrier facilities bacterial translocation of live bacteria or their microbial products from the intestinal lumen to the liver, via portal circulation, and to systemic circulation and the lung via the mesenteric lymphatic system $[29,101]$. In the lung and the liver, gut microbiota can directly modulate their local immune cells (mainly alveolar macrophages and Kupffer cells, respectively) via activation of toll-like receptors (TLRs) and indirectly via different bacterial metabolites and signaling molecules, such as PAMPs [29, 48, 49, 90]. Activated alveolar macrophages in the lung and Kupffer cells in the liver release proinflammatory cytokines, contributing to the initiation and/or progression of lung and liver damage and activation of systemic inflammation [29, 101], which can also cause dysfunction in other organs.

Second, liver dysfunction can imply less capacity of the liver to remove bacteria, bacterial products, and inflammatory mediators from circulation, leading to increased levels of these molecules in blood.

Third, this pathological gut-derived bacterial translocation could cause important changes in the lung microbiome (Fig. 2) [90, 102, 103]. Indeed, pulmonary microbiome is frequently enriched with gut-related bacteria (Bacteroidetes and Enterobacteriaceae) in critically ill patients [102, 103]. As a consequence of liver diseases, this gut-derived bacteria and accumulation of PAMPs, cytokines and other pro-inflammatory molecules in the systemic circulation can potentially cause or exacerbate lung injury upon TLR-4-mediated activation of intravascular and alveolar macrophages within the lung and recruitment of neutrophils and direct toxic effects of bacterial products on pulmonary microvasculature (Fig. 2) [68, 102-108]. Altogether, the gut-liver-lung axis seems to exert a relevant role in the initiation and modulation of hepatic, pulmonary, and systemic immune responses that contribute to the damage of the liver, the lung, and other organs. 


\section{Extracellular vesicles}

Extracellular vesicles (EVs), a term that includes microvesicles (MVs), exosomes, and apoptotic bodies, represent an emerging mechanism of interorgan communication in many diseases, including liver diseases and ARDS [106, 109-111]. Extracellular vesicles are defined as membrane-bound vesicles, ranging $0.1-1.0 \mu \mathrm{m}$ in diameter, which are released from cells by the budding of the cellular plasma membrane and carrying a diverse cargo, including lipids, proteins, RNAs, and miRNAs. The EVs are recognized as important mediators of interaction between different organs, and they are considered attractive therapeutic targets in different diseases [112, 113]. Notably, the levels of circulating EVs have been reported to be increased both in patients with cirrhosis and ARDS. However, the potential role of circulating EVs in mediating liver-lung communication in the context of ARDS is not currently understood, representing an interesting topic for further investigation.

\section{Conclusions}

Liver injury and hepatotoxicity occur frequently in critically ill patients, and significantly influence their prognosis. Patients with severe hepatic dysfunction are at high risk for irreversible ARDS because of multiple defects in host defense and dysregulation of inflammatory responses. Interrelations between hepatic and pulmonary functions influence the development and progression of ARDS and play a central role in the resolution of lung damage by several mechanisms. First, the liver regulates host defense and modulates systemic inflammation. Also, the liver activates acute inflammatory responses in the lung early in the development of ARDS. Although promoting inflammation can be detrimental in the context of acute lung injury, the liver response to an inflammatory insult is also pro-defense and pro-survival. The understanding of the complex relation between the liver and the lung requires further research in order to improve the clinical management and to identify new diagnostic and therapeutic options for patients with or at risk for ARDS.

\footnotetext{
Abbreviations

ARDS: Acute respiratory distress syndrome; DAD: Diffuse alveolar damage; ICU: Intensive care unit; AST: Aspartate aminotransferase; ALT: Alanine aminotransferase; ALP: Alkaline phosphatase; INR: International normalized ratio; PAMPs: Pathogen-associated molecular patterns; TLRs: Toll-like receptors; IL: Interleukin; ENA-78: Epithelial neutrophilactivating peptide-78; TNF: Tumor necrosis factor; MCP-1: Monocyte chemoattractant protein-1; MIP-1a: Macrophage inflammatory protein-1a; PAF: Platelet-activating factor; CCI4: Carbon tetrachloride; TBARS: Thiobarbituric acid-reactive substances; APPS: Acute-phase proteins; LPS: Lipopolysaccharides; STAT3: Signal transducer and activator of transcription 3; RelA: v-rel avian reticuloendotheliosis viral oncogene homolog A; NF-kB3: Nuclear factor kappa-lightchain-enhancer of activated B3; SAA: Serum amyloid A; SAP: Serum amyloid P; LBP: Lipopolysaccharide binding protein; CXCL1: Chemokine (C-X-C motif) ligand 1; EVs: Extracellular vesicles; MVs: Microvesicles; RNAs: Ribonucleic acids; miRNAs: Micro-ribonucleic acids
}

Acknowledgements

Not applicable

About this supplement

This article has been published as part of Intensive Care Medicine Experimental Volume 8 Supplement 1, 2020:

Proceedings from the Fourth International Symposium on Acute Pulmonary Injury and Translation Research (INSPIRES

IV). The full contents of the supplement are available at https://icm-experimental.springeropen.com/articles/

supplements/volume-8-supplement-1.

Authors' contributions

$\mathrm{RH}$ and GS did the design, acquisition of information, and drafting and revising the manuscript. IA, EL, AF, and AdL were responsible for the acquisition of information. JV, LM, RB, and JAL did the revising of the work. The authors read and approved the final manuscript. 
Funding

This study was funded with grants Pl12/02451, PI15/00482 and PI19/01091 (to RH) and PI15/01942 (to JAL) from the Instituto de Salud Carlos III, Ministerio de Economia y Competitividad, Madrid, Spain. Also, another funding with grant, B2017/BMD-3727-EXOHEP-CM (to RB and JAL) was from the Comunidad de Madrid and Fondos FEDER "Una manera de hacer Europa", Madrid, Spain.

\section{Availability of data and materials}

Not applicable

\section{Ethics approval and consent to participate}

Not applicable

\section{Consent for publication}

Not applicable

\section{Competing interests}

The authors declare that they have no competing interests.

\section{Author details}

${ }^{1}$ Department of Critical Care Medicine, Hospital Universitario de Getafe, Madrid, Spain. ${ }^{2}$ CIBER de Enfermedades Respiratorias, Instituto de Investigación Carlos III, Madrid, Spain. ${ }^{3}$ Fundación de Investigación Biomédica del Hospital Universitario de Getafe, Madrid, Spain. ${ }^{4}$ Laboratory of Biochemistry, Hospital Universitario de Getafe, Madrid, Spain. ${ }^{5}$ Servicio de Aparato Digestivo. HGU Gregorio Marañón, Instituto de Investigación Sanitaria Gregorio Marañón (liSGM), Madrid, Spain. ${ }^{6} \mathrm{CIBER}$ de Enfermedades Hepáticas y Digestivas, Instituto de Investigación Carlos III, Madrid, Spain. ${ }^{7}$ Department of Pharmacology, School of Medicine, Universidad Complutense de Madrid, Madrid, Spain. ${ }^{8}$ Universidad Europea de Madrid, Madrid, Spain.

Received: 14 July 2020 Accepted: 16 July 2020

Published: 18 December 2020

\section{References}

1. Definition Task Force ARDS, Ranieri VM, Rubenfeld GD, Thompson BT, Ferguson ND, Caldwell E et al (2012) Acute respiratory distress syndrome: the Berlin definition. JAMA 307(23):2526-2533

2. Matthay MA, Ware LB, Zimmerman GA (2012) The acute respiratory distress syndrome. J Clin Invest 122(8):2731-2740

3. Bellani G, Laffey JG, Pham T, Fan E, Brochard L, Esteban A et al (2016) Epidemiology, patterns of care, and mortality for patients with acute respiratory distress syndrome in intensive care units in 50 countries. JAMA 315(8):788-800

4. Matthay MA, Zemans RL (2011) The acute respiratory distress syndrome: pathogenesis and treatment. Annu Rev Pathol 6:147-163

5. Matuschak GM, Rinaldo JE (1988) Organ interactions in the adult respiratory distress syndrome during sepsis. Role of the liver in host defense. Chest 94(2):400-406

6. Rogers DE (1960) Host mechanisms which act to remove bacteria from the blood stream. Bacteriol Rev 24(1):50-66

7. Kolaczkowska E, Jenne CN, Surewaard BGJ, Thanabalasuriar A, Lee W-Y, Sanz M-J et al (2015) Molecular mechanisms of NET formation and degradation revealed by intravital imaging in the liver vasculature. Nat Commun 6:6673

8. Kaplan JE, Saba TM (1978) Platelet removal from the circulation by the liver and spleen. Am J Phys 235(3):H314-H320

9. Bradfield JW (1974) Control of spillover. The importance of Kupffer-cell function in clinical medicine. Lancet Lond Engl 2(7885):883-886

10. Guillot A, Tacke F (2019) Liver macrophages: old dogmas and new insights. Hepatol Commun 3(6):730-743

11. Khanlou H, Souto H, Lippmann M, Muñoz S, Rothstein K, Ozden Z (1999) Resolution of adult respiratory distress syndrome after recovery from fulminant hepatic failure. Am J Med Sci 317(2):134-136

12. Ali M, Wall WJ (1990) Resolution of the adult respiratory distress syndrome following colectomy and liver transplantation. Chest 98(4):1032-1034

13. Doyle HR, Marino IR, Miro A, Scott V, Martin M, Fung J et al (1993) Adult respiratory distress syndrome secondary to end-stage liver disease - successful outcome following liver transplantation. Transplantation 55(2):292-296

14. Siore AM, Parker RE, Stecenko AA, Cuppels C, McKean M, Christman BW et al (2005) Endotoxin-induced acute lung injury requires interaction with the liver. Am J Physiol Lung Cell Mol Physiol 289(5):L769-L776

15. Matuschak GM (1994) Liver-lung interactions in critical illness. New Horiz 2(4):488-504

16. Cerra FB, West M, Billiar TR, Holman RT, Simmons R (1989) Hepatic dysfunction in multiple systems organ failure as a manifestation of altered cell-cell interaction. Prog Clin Biol Res 308:563-573

17. Matuschak GM (1996) Lung-liver interactions in sepsis and multiple organ failure syndrome. Clin Chest Med 17(1):83-98

18. Wang Y, Liu W, Liu X, Sheng M, Pei Y, Lei R et al (2015) Role of liver in modulating the release of inflammatory cytokines involved in lung and multiple organ dysfunction in severe acute pancreatitis. Cell Biochem Biophys $71(2): 765-776$

19. Matuschak GM, Martin DJ (1987) Influence of end-stage liver failure on survival during multiple systems organ failure Transplant Proc 19(4 Suppl 3):40-46

20. Katz S, Grosfeld JL, Gross K, Plager DA, Ross D, Rosenthal RS et al (1984) Impaired bacterial clearance and trapping in obstructive jaundice. Ann Surg 199(1):14-20

21. Loegering DJ, Blumenstock FA (1985) Depressing hepatic macrophage complement receptor function causes increased susceptibility to endotoxemia and infection. Infect Immun 47(3):659-664

22. DeCamp MM, Warner AE, Molina RM, Brain JD (1992) Hepatic versus pulmonary uptake of particles injected into the portal circulation in sheep. Endotoxin escapes hepatic clearance causing pulmonary inflammation. Am Rev Respir Dis 146(1):224-231 
23. Hawker $F$ (1991) Liver dysfunction in critical illness. Anaesth Intensive Care 19(2):165-181

24. Yang P, Formanek P, Scaglione S, Afshar M (2019) Risk factors and outcomes of acute respiratory distress syndrome in critically ill patients with cirrhosis. Hepatol Res Off J Jpn Soc Hepatol 49(3):335-343

25. Gacouin A, Locufier M, Uhel F, Letheulle J, Bouju P, Fillatre P et al (2016) Liver cirrhosis is independently associated with 90-day mortality in ARDS patients. Shock 45(1):16-21

26. Schwartz DB, Bone RC, Balk RA, Szidon JP (1989) Hepatic dysfunction in the adult respiratory distress syndrome. Chest 95(4):871-875

27. Wang CY, Calfee CS, Paul DW, Janz DR, May AK, Zhuo H et al (2014) One-year mortality and predictors of death among hospital survivors of acute respiratory distress syndrome. Intensive Care Med 40(3):388-396

28. Dong V, Sun K, Gottfried M, Cardoso FS, McPhail MJ, Stravitz RT et al (2020) Significant lung injury and its prognostic significance in acute liver failure: a cohort analysis. Liver Int Off J Int Assoc Study Liver 40(3):654-663

29. Albillos A, Gottardi A, de Rescigno M (2019) The gut-liver axis in liver disease: pathophysiological basis for therapy. J Hepatol

30. Matuschak GM, Mattingly ME, Tredway TL, Lechner AJ (1994) Liver-lung interactions during E. coli endotoxemia. TNFalpha:leukotriene axis. Am J Respir Crit Care Med 149(1):41-49

31. Patterson EK, Yao LJ, Ramic N, Lewis JF, Cepinskas G, McCaig L et al (2013) Lung-derived mediators induce cytokine production in downstream organs via an NF-kB-dependent mechanism. Mediat Inflamm 2013:586895

32. Karcz M, Bankey B, Schwaiberger D, Lachmann B, Papadakos PJ (2012) Acute respiratory failure complicating advanced liver disease. Semin Respir Crit Care Med 33(1):96-110

33. Horvatits T, Drolz A, Trauner M, Fuhrmann V. Liver injury and failure in critical illness. Hepatol 2019;

34. Kramer L, Jordan B, Druml W, Bauer P, Metnitz PGH, Austrian Epidemiologic Study on Intensive Care, ASDI Study Group et al (2007) Crit Care Med 35(4):1099-1104

35. Dizier S, Forel J-M, Ayzac L, Richard J-C, Hraiech S, Lehingue S et al (2015) Early hepatic dysfunction is associated with a worse outcome in patients presenting with acute respiratory distress syndrome: a post-hoc analysis of the ACURASYS and PROSEVA studies. PLoS One 10(12):e0144278

36. Lescot T, Karvellas C, Beaussier M, Magder S (2012) Acquired liver injury in the intensive care unit. Anesthesiology 117(4): 898-904

37. Marshall JC (2013) The liver in sepsis: shedding light on the cellular basis of hepatocyte dysfunction. Crit Care Lond Engl 17(3):153

38. Fuhrmann V, Kneidinger N, Herkner H, Heinz G, Nikfardjam M, Bojic A et al (2011) Impact of hypoxic hepatitis on mortality in the intensive care unit. Intensive Care Med 37(8):1302-1310

39. Zhai R, Sheu CC, Su L, Gong MN, Tejera P, Chen F et al (2009) Serum bilirubin levels on ICU admission are associated with ARDS development and mortality in sepsis. Thorax 64(9):784-790

40. Kortgen A, Paxian M, Werth M, Recknagel P, Rauchfuss F, Lupp A et al (2009) Prospective assessment of hepatic function and mechanisms of dysfunction in the critically ill. Shock 32(4):358-365

41. Sakka SG (2007) Assessing liver function. Curr Opin Crit Care 13(2):207-214

42. Vincent JL, Moreno R, Takala J, Willatts S, De Mendonça A, Bruining H et al (1996) The SOFA (sepsis-related organ failure assessment) score to describe organ dysfunction/failure. On behalf of the working group on sepsis-related problems of the European Society of Intensive Care Medicine. Intensive Care Med 22(7):707-710

43. Sheu C-C, Gong MN, Zhai R, Chen F, Bajwa EK, Clardy PF et al (2010) Clinical characteristics and outcomes of sepsisrelated vs non-sepsis-related ARDS. Chest 138(3):559-567

44. Praaning-van Dalen DP, Brouwer A, Knook DL (1981) Clearance capacity of rat liver Kupffer, endothelial, and parenchymal cells. Gastroenterology 81(6):1036-1044

45. Freudenberg MA, Freudenberg N, Galanos C (1982) Time course of cellular distribution of endotoxin in liver, lungs and kidneys of rats. Br J Exp Pathol 63(1):56-65

46. Bilzer M, Roggel F, Gerbes AL (2006) Role of Kupffer cells in host defense and liver disease. Liver Int Off J Int Assoc Study Liver 26(10):1175-1186

47. Triantafyllou E, Woollard KJ, MJW MP, Antoniades CG, Possamai LA (2018) The role of monocytes and macrophages in acute and acute-on-chronic liver failure. Front Immunol 9:2948

48. Young RP, Hopkins RJ, Marsland B (2016) The gut-liver-lung axis, Modulation of the innate immune response and its possible role in chronic obstructive pulmonary disease. Am J Respir Cell Mol Biol 54(2):161-169

49. Enaud R, Prevel R, Ciarlo E, Beaufils F, Wieërs G, Guery B, et al. The gut-lung axis in health and respiratory diseases: a place for inter-organ and inter-kingdom crosstalks. Front Cell Infect Microbiol [Internet]. 19 de febrero de 2020 [citado 1 de julio de 2020];10. Disponible en: https://www.ncbi.nlm.nih.gov/pmc/articles/PMC7042389/

50. Tarao K, Moroi T, Nagakura Y, Ikeuchi T, Suyama T, Endo O et al (1979) Relationship between endotoxaemia and protein concentration of ascites in cirrhotic patients. Gut 20(3):205-210

51. Tilg H, Wilmer A, Vogel W, Herold M, Nölchen B, Judmaier G et al (1992) Serum levels of cytokines in chronic liver diseases. Gastroenterology 103(1):264-274

52. Khoruts A, Stahnke L, McClain CJ, Logan G, Allen JI (1991) Circulating tumor necrosis factor, interleukin-1 and interleukin-6 concentrations in chronic alcoholic patients. Hepatol 13(2):267-276

53. Devière J, Content J, Denys C, Vandenbussche P, Schandene L, Wybran J et al (1990) Excessive in vitro bacterial lipopolysaccharide-induced production of monokines in cirrhosis. Hepatol 11(4):628-634

54. Torre D, Zeroli C, Giola M, Ferrario G, Fiori GP, Bonetta G et al (1994) Serum levels of interleukin-1 alpha, interleukin-1 beta, interleukin-6, and tumor necrosis factor in patients with acute viral hepatitis. Clin Infect Dis Off Publ Infect Dis Soc Am 18(2):194-198

55. Kobayashi K, Horikami D, Omori K, Nakamura T, Yamazaki A, Maeda S et al (2016) Thromboxane A2 exacerbates acute lung injury via promoting edema formation. Sci Rep 6:32109

56. Park WY, Goodman RB, Steinberg KP, Ruzinski JT, Radella F, Park DR et al (2001) Cytokine balance in the lungs of patients with acute respiratory distress syndrome. Am J Respir Crit Care Med 164(10 Pt 1):1896-1903

57. Goodman RB, Strieter RM, Martin DP, Steinberg KP, Milberg JA, Maunder RJ et al (1996) Inflammatory cytokines in patients with persistence of the acute respiratory distress syndrome. Am J Respir Crit Care Med 154(3 Pt 1):602-611 
58. Wiedermann FJ, Mayr AJ, Kaneider NC, Fuchs D, Mutz NJ, Schobersberger W (2004) Alveolar granulocyte colonystimulating factor and alpha-chemokines in relation to serum levels, pulmonary neutrophilia, and severity of lung injury in ARDS. Chest 125(1):212-219

59. Frank JA, Matthay MA (2005) Leukotrienes in acute lung injury. Am J Respir Crit Care Med 172(3):261-262

60. Rojas M, Woods CR, Mora AL, Xu J, Brigham KL (2005) Endotoxin-induced lung injury in mice: structural, functional, and biochemical responses. Am J Physiol Lung Cell Mol Physiol 288(2):L333-L341

61. Panos RJ, Baker SK (1996) Mediators, cytokines, and growth factors in liver-lung interactions. Clin Chest Med 17(1):151-169

62. Tran-Thi TA, Weinhold L, Weinstock C, Hoffmann R, Schulze-Specking A, Northoff H et al (1993) Production of tumor necrosis factor-alpha, interleukin-1 and interleukin-6 in the perfused rat liver. Eur Cytokine Netw 4(5):363-370

63. Ramadori G, Christ B (1999) Cytokines and the hepatic acute-phase response. Semin Liver Dis 19(2):141-155

64. Hermanns Ml, Kasper J, Dubruel P, Pohl C, Uboldi C, Vermeersch V et al (2010) An impaired alveolar-capillary barrier in vitro: effect of proinflammatory cytokines and consequences on nanocarrier interaction. J R Soc Interface 7(Suppl 1): S41-S54

65. Callery MP, Kamei T, Mangino MJ, Flye MW (1991) Organ interactions in sepsis. Host defense and the hepatic-pulmonary macrophage axis. Arch Surg Chic III 1960 126(1):28-32

66. Ferrari RS, Tieppo M, da RDP, Forgiarini LA, Dias AS, Marroni NP (2013) Lung and liver changes due to the induction of cirrhosis in two experimental models. Arq Gastroenterol 50(3):208-213

67. Salatti Ferrari R, da Rosa DP, Forgiarini LF, Bona S, Dias AS, Marroni NP (2012) Oxidative stress and pulmonary changes in experimental liver cirrhosis. Oxidative Med Cell Longev 2012:486190

68. Massey VL, Poole LG, Siow DL, Torres E, Warner NL, Schmidt RH et al (2015) Chronic alcohol exposure enhances lipopolysaccharide-induced lung injury in mice: potential role of systemic tumor necrosis factor-alpha. Alcohol Clin Exp Res 39(10):1978-1988

69. Halbertsma FJJ, Vaneker M, Scheffer GJ, van der Hoeven JG. Cytokines and biotrauma in ventilator-induced lung injury: a critical review of the literature. Neth J Med 2005;63(10):382-392.

70. Seekamp A, Warren JS, Remick DG, Till GO, Ward PA (1993) Requirements for tumor necrosis factor-alpha and interleukin-1 in limb ischemia/reperfusion injury and associated lung injury. Am J Pathol 143(2):453-463

71. Ahuja N, Andres-Hernando A, Altmann C, Bhargava R, Bacalja J, Webb RG et al (2012) Circulating IL-6 mediates lung injury via CXCL1 production after acute kidney injury in mice. Am J Physiol Renal Physiol 303(6):F864-F872

72. Zhang H, Neuhöfer P, Song L, Rabe B, Lesina M, Kurkowski MU et al (2013) IL-6 trans-signaling promotes pancreatitisassociated lung injury and lethality. J Clin Invest 123(3):1019-1031

73. Quinton LJ, Jones MR, Robson BE, Mizgerd JP (2009) Mechanisms of the hepatic acute-phase response during bacterial pneumonia. Infect Immun 77(6):2417-2426

74. Gabay C, Kushner I (1999) Acute-phase proteins and other systemic responses to inflammation. N Engl J Med 340(6): 448-454

75. Suffredini AF, Fantuzzi G, Badolato R, Oppenheim JJ, O'Grady NP (1999) New insights into the biology of the acute phase response. J Clin Immunol 19(4):203-214

76. Weber M, Lambeck S, Ding N, Henken S, Kohl M, Deigner HP et al (2012) Hepatic induction of cholesterol biosynthesis reflects a remote adaptive response to pneumococcal pneumonia. FASEB J Off Publ Fed Am Soc Exp Biol 26(6):2424-2436

77. Gamble L, Bagby GJ, Quinton LJ, Happel Kl, Mizgerd JP, Zhang P et al (2009) The systemic and pulmonary LPS binding protein response to intratracheal lipopolysaccharide. Shock 31(2):212-217

78. Quinton L, Jones MR, Robson BE, Simms BT, Whitsett JA, Mizgerd JP (2008) Alveolar epithelial STAT3, IL-6 family cytokines, and host defense during Escherichia coli pneumonia. Am J Respir Cell Mol Biol 38(6):699-706

79. Quinton LJ, Blahna MT, Jones MR, Allen E, Ferrari JD, Hilliard KL et al (2012) Hepatocyte-specific mutation of both NF-KB RelA and STAT3 abrogates the acute phase response in mice. J Clin Invest 122(5):1758-1763

80. Niemi K, Teirilä L, Lappalainen J, Rajamäki K, Baumann MH, Öörni K et al (2011) Serum amyloid a activates the NLRP3 inflammasome via P2X7 receptor and a cathepsin B-sensitive pathway. J Immunol 186(11):6119-6128

81. Shah C, Hari-Dass R, Raynes JG, Serum amyloid A (2006) Is an innate immune opsonin for gram-negative bacteria. Blood 108(5):1751-1757

82. Zhang W, Xu W, Xiong S (2011) Macrophage differentiation and polarization via phosphatidylinositol 3-kinase/Akt-ERK signaling pathway conferred by serum amyloid P component. J Immunol 187(4):1764-1777

83. Tobias PS, Mathison J, Mintz D, Lee JD, Kravchenko V, Kato K et al (1992) Participation of lipopolysaccharide-binding protein in lipopolysaccharide-dependent macrophage activation. Am J Respir Cell Mol Biol 7(3):239-245

84. Mold C, Du Clos TW (2006) C-reactive protein increases cytokine responses to Streptococcus pneumoniae through interactions with fc gamma receptors. J Immunol 176(12):7598-7604

85. Barna BP, Deodhar SD, Gautam S, Yen-Lieberman B, Roberts D (1984) Macrophage activation and generation of tumoricidal activity by liposome-associated human C-reactive protein. Cancer Res 44(1):305-310

86. Hilliard KL, Allen E, Traber KE, Yamamoto K, Stauffer NM, Wasserman GA et al (2015) The lung-liver axis: a requirement for maximal innate immunity and hepatoprotection during pneumonia. Am J Respir Cell Mol Biol 53(3):378-390

87. Frank JA, Wray CM, McAuley DF, Schwendener R, Matthay MA (2006) Alveolar macrophages contribute to alveolar barrier dysfunction in ventilator-induced lung injury. Am J Physiol Lung Cell Mol Physiol 291(6):L1191-L1198

88. Renckens R, van Westerloo DJ, Roelofs JJTH, Pater JM, Schultz MJ, Florquin S et al (2008) Acute phase response impairs host defense against Pseudomonas aeruginosa pneumonia in mice. Crit Care Med 36(2):580-587

89. Renckens R, Roelofs JJTH, Knapp S, de Vos AF, Florquin S, van der Poll T (2006) The acute-phase response and serum amyloid a inhibit the inflammatory response to Acinetobacter baumannii pneumonia. J Infect Dis 193(2):187-195

90. Sakamori R, Takehara T, Ohnishi C, Tatsumi T, Ohkawa K, Takeda K et al (2007) Signal transducer and activator of transcription 3 signaling within hepatocytes attenuates systemic inflammatory response and lethality in septic mice. Hepatol 46(5):1564-1573

91. Postic C, Dentin R, Girard J (2004) Role of the liver in the control of carbohydrate and lipid homeostasis. Diabetes Metab 30(5):398-408

92. Hofmann AF (1999) The continuing importance of bile acids in liver and intestinal disease. Arch Intern Med 159(22): $2647-2658$ 
93. Rui L (2014) Energy metabolism in the liver. Compr Physiol 4(1):177-197

94. Dani C, Martelli E, Tronchin M, Buonocore G, Longini M, Di Filippo A et al (2004) Bilirubin influence on oxidative lung damage and surfactant surface tension properties. Pediatr Pulmonol 38(3):179-185

95. Chopra M, Reuben JS, Sharma AC (2009) Acute lung injury:apoptosis and signaling mechanisms. Exp Biol 234(4):361-37

96. Rodrigues CMP, Solá S, Brito MA, Brites D, Moura JJG (2002) Bilirubin directly disrupts membrane lipid polarity and fluidity, protein order, and redox status in rat mitochondria. J Hepatol 36(3):335-341

97. Cesaratto L, Calligaris SD, Vascotto C, Deganuto M, Bellarosa C, Quadrifoglio F et al (2007) Bilirubin-induced cell toxicity involves PTEN activation through an APE1/Ref-1-dependent pathway. J Mol Med 85(10):1099-1112

98. Fernandes A, Falcão AS, Silva RFM, Gordo AC, Gama MJ, Brito MA et al (2006) Inflammatory signalling pathways involved in astroglial activation by unconjugated bilirubin. J Neurochem 96(6):1667-1679

99. Cuccurullo A, Greco E, Lupia E, De Giuli P, Bosco O, Martin-Conte E et al (2016) Blockade of thrombopoietin reduces organ damage in experimental endotoxemia and polymicrobial sepsis. PLoS One 11(3):e0151088

100. Wang Z, Li W, Guo Q, Wang Y, Ma L, Zhang X (2018) Insulin-like growth factor-1 signaling in lung development and inflammatory lung diseases. Biomed Res Int 2018:6057589

101. Acharya C, Sahingur SE, Bajaj JS. Microbiota, cirrhosis, and the emerging oral-gut-liver axis. JCl Insight. 05 de 2017;2(19).

102. Dickson RP (2018) The lung microbiome and ARDS. It is time to broaden the model. Am J Respir Crit Care Med 197(5): 549-551

103. Mukherjee S, Hanidziar D (2018) More of the gut in the lung: how two microbiomes meet in ARDS. Yale J Biol Med 91(2):143-149

104. Dickson RP, Singer BH, Newstead MW, Falkowski NR, Erb-Downward JR, Standiford TJ et al (2016) Enrichment of the lung microbiome with gut bacteria in sepsis and the acute respiratory distress syndrome. Nat Microbiol 1(10):16113

105. Deitch EA (2010) Gut lymph and lymphatics: a source of factors leading to organ injury and dysfunction. Ann N Y Acad Sci 1207(Suppl 1):E103-E111

106. Kojima M, Gimenes-Junior JA, Chan TW, Eliceiri BP, Baird A, Costantini TW et al (2018) Exosomes in postshock mesenteric lymph are key mediators of acute lung injury triggering the macrophage activation via toll-like receptor 4. FASEB J Off Publ Fed Am Soc Exp Biol 32(1):97-110

107. de Jong PR, González-Navajas JM, Jansen NJG (2016) The digestive tract as the origin of systemic inflammation. Crit Care Lond Engl 20(1):279

108. Massey VL (2015) Potential role of the gut/liver/lung axis in alcohol-induced tissue pathology. Biomolecules 5(4):2477-2503

109. Hirsova P, Ibrahim SH, Verma VK, Morton LA, Shah VH, LaRusso NF et al (2016) Extracellular vesicles in liver pathobiology: small particles with big impact. Hepatol 64(6):2219-2233

110. Maji S, Matsuda A, Yan IK, Parasramka M, Patel T (2017) Extracellular vesicles in liver diseases. Am J Physiol Gastrointest Liver Physiol 312(3):G194-G200

111. Malhi H (2019) Emerging role of extracellular vesicles in liver diseases. Am J Physiol Gastrointest Liver Physiol 317(5): G739-G749

112. McVey M, Tabuchi A, Kuebler WM (2012) Microparticles and acute lung injury. Am J Physiol Lung Cell Mol Physiol 303(5):L364-L381

113. Rautou P-E, Bresson J, Sainte-Marie Y, Vion A-C, Paradis V, Renard J-M et al (2012) Abnormal plasma microparticles impair vasoconstrictor responses in patients with cirrhosis. Gastroenterology 143(1):166-176.e6

\section{Publisher's Note}

Springer Nature remains neutral with regard to jurisdictional claims in published maps and institutional affiliations.

\section{Submit your manuscript to a SpringerOpen ${ }^{\circ}$ journal and benefit from:}

- Convenient online submission

- Rigorous peer review

- Open access: articles freely available online

- High visibility within the field

- Retaining the copyright to your article

Submit your next manuscript at $\boldsymbol{\nabla}$ springeropen.com 